\title{
EFEITOS DA INTERAÇÃO DE ÁCIDO FERÚLICO E GLIFOSATE EM SOJA ${ }^{1}$
}

\author{
ELEMAR VOLL ${ }^{2}$
}

RESUMO

\begin{abstract}
Um experimento foi conduzido com soja [Glycine max (L.) Men.] cv. Ramson, em condições de casa-de-vegetação, com o objetivo de obter respostas de crescimento ao herbicida glifosate [N-(fosfonometil) glicina] (GLI), com atividades hormonais, em interação com ácido ferúlico (ácido 4hidróxi-3-metóxi-t-cinâmico) (AF), substância alelopática encontrada na resteva de trigo em situações de semeadura direta, que pudessem favorecer sua competição com as espécies daninhas. Glifosate foi usado nas doses de 0,0,0,75, $1,5,2,25$ e 3,0 kg/ha e ácido ferúlico nas doses de 0,75, 150, 225 e 300 ppm. O delineamento experimental foi de blocos
\end{abstract}

ao acaso em um arranjo fatorial $5 \times 5$ dos tratamentos, com quatro repetições. Vasos de papel encerado continham $1,0 \mathrm{~kg}$ de terra na proporção de 3:2 (argila/areia), com duas plantas/vaso. A duração do experimento foi de 22 dias. Aplicações de AF e GLI causaram estiolamento da parte aérea das plantas de soja e redução da biomassa das raízes. Foram observados aumentos da biomassa da parte aérea da soja por AF e reduções por GLI.

Palavras-chave: Glycine max, semeadura direta, resteva, alelopatia.

\section{ABSTRACT \\ Interaction of ferulic acid and glyphosate on soybeans}

An experiment was carried out for soybeans [Glycine $\max (L$.) Men.] cv. Ramson, under greenhouse conditions, to evaluate its growing responses to glyphosate [N-(phosphonomethyl) gycine] (GLY), a herbicide with hormonal action, in interaction with ferulic acid (4-hydroxy-3methoxy-t-cinnamic acid) (FA), an allelopathic substance found in wheat straw under no-till plantings, which in combination could favour competition against weeds. Doses of $0.00,0.75,1.50,2.25$ and $3.00 \mathrm{~kg} / \mathrm{ha}$ of glyphosate and 0 , $75,150,225$ and $300 \mathrm{ppm}$ of ferulic acid were used. A

\section{INTRODUÇÃO}

Substâncias fitotóxicas, como o ácido ferúlico, presentes em resíduos de trigo em decomposição, em lavouras de semeadura direta, são capazes de afetar a germinação e o crescimento da cultura, como a soja, sendo de maior impor-

1 Recebido para publicação em 21/03/93 e na forma revisada em 20/06/93. 2 Eng $^{\circ}$ Agr., Ph.D., Pesquisador da EMBRAPA/CNPSo, Caixa Posta1 1061, CEP 86001-970, Londrina, PR. randomized block design in factorial $5 \times 5$, with four replications was used. Paper pots were filled with $1,0 \mathrm{~kg}$ of mixed soil (3:2 clay/sand), with two plants/pot. The duration of experiment was 22 days. Applications of FA and GLY caused etiolation of soybean shoots and decrease of root biomass. Increases of soybean shoot biomass observed for FA were reduced by GLY.

Additional index words: Glycine max, no-till, mulch, allelopathy.

tância no controle de diferentes espécies de plantas daninhas (Almeida \& Rodrigues, 1984; Cochran et al., 1977; Collins \& Caviness, 1978; Guenzi \& McCalla, 1962; Liebl \& Worsham, 1983; Steinsiek et al., 1980; Voll, 1986). As condições ambientais que precedem a formação e/ou liberação das substâncias fitotóxicas ori ginadas das coberturas mortas (restevas) são geralmente de umidade e baixas temperaturas (Cochran et al., 1977). 0 aumento da precipitação anual, que favorece aumentos de restos de culturas imediatamente anteriores e sua posterior lixiviação, tem mostrado correlação 
com a redução de produção de culturas subseqüentes (Papendick \& Miller, 1977). A toxicidade do solo, devida a estes constituintes orgânicos, mostra-se mais freqüientemente associada a solos pesados, mal arejados, ou inundados (Patrick \& Koch, 1958). Métodos de preparo do solo podem influir na produção destas substâncias fitotóxicas (Liebl \& Worsham, 1983).

Glifosate tem sido um dos herbicidas não seletivos de manejo mais usados no controle de plantas daninhas em semeadura direta, onde há manutenção da resteva da cultura anterior, em plantios de milho e soja (Hardcastle, 1972; Williamson, 1978; Worsham \& Lewis, 1972). 0 glifosate é um herbicida sistêmico usado contra invasoras anuais e perenes e, aparentemente, não mostra atividade residual no solo (Baird et al., 1971). Maiores produções de milho e soja têm sido relatadas com o seu uso, como resultado de um controle de gramíneas anuais por um período mais prolongado (Worsham \& Lewis, 1972). Por sua vez, aplicações de doses subletais de glifosate têm aumentado a biomassa de plântulas de sorgo (Baur et al., 1976). Exsudações de glifosate, aplicado em plantas de trigo, resultaram em aumentos de altura de planta e de biomassa de soja 'Ramson', plantada posteriormente (Rodrigues et al., 1982). Glifosate, aplicado em aveia, tem sido absorvido por plantas de milho, afetando o seu crescimento (Williamson, 1978).

Os objetivos do experimento foram determinar os efeitos da absorção de ácido fenúlico e de glifosate, isolados e em interação, no crescimento da soja.

\section{MATERIAL E MÉTODOS}

O experimento foi conduzido em casa-de-vegetação, em vasos de papel encerado com $1250 \mathrm{~g}$ de terra seca ao ar e peneirada, na razão de 3:2 argila/areia, nos quais foi determinada a capacidade de campo. Foram feitos furos na base dos vasos para drenagem e escoamento de água. Soja cv. 'Ramson' foi plantada, usando quatro sementes/vaso, a $2 \mathrm{~cm}$ de profundidade. Soluções padrões de ácido ferúlico (ácido 4hidróxi-3 -metóxi-t-cinâmico) (AF) foram preparadas em água e tamponadas com $\mathrm{Na}_{2} \mathrm{HPO}_{4}(1,0 \mathrm{M})$ para alcançar $\mathrm{pH}$ 6,0 e facilitar a sua solubilização. As doses de ácido ferúlico usadas foram $0,75,150,225$ e 300 ppm. Uma metade de cada dose foi aplicada no plantio e a outra quatro dias após a emergência. As soluções foram derramadas sobre o solo nos vasos, baseado na capacidade de campo previamente determinada. O glifosate [N-(fosfonometil) glicina] (GLI) foi pulverizado após a aplicação parcial das doses de ácido ferúlico, usando um pulverizador costal a $\mathrm{CO}_{2}$, com barra de pulverização sustentando um bico em cone, 110.02 , pressão de 1,4 $\mathrm{kgf} / \mathrm{cm}^{2}$ e com consumo de calda de $172 \mathrm{I} / \mathrm{ha}$. As doses de glifosate usadas foram $0,0,75,1,50,2,25$ e 3,00 kg/ha. Por ocasião da aplicação da segunda meia-dose do ácido ferúlico, a soja foi raleada para duas plantas/vaso. A solução nutritiva de Hoagland foi usada uma vez por semana para suprir os nutrientes necessários. A irrigação foi feita sempre que necessária para manter a umidade acima de $50 \%$ da capacidade de campo. As determinações finais foram: a) altura de planta de soja, medida da base até a inserção da gema terminal; b) biomassa fresca da parte aérea e, c) biomassa seca das raízes. A duração do experimento foi de 22 dias. O delineamento experimental foi um fatorial $5 \times 5$ dos tratamentos em blocos ao acaso, com quatro repetições. Os dados foram submetidos a análise da variância de regressão para as variáveis altura de planta, biomassa aérea e das raízes, com as combinações de doses de ácido ferúlico e glifosate. Nas análises de regressão foram testados os modelos linear, quadrático e cúbico, para parâmetros significativos pelo F-teste.

\section{RESULTADOS E DISCUSSÃO}

A altura das plantas de soja (Figura 1) aumentou linearmente com doses crescentes de AF, tanto na ausência como a $0,75 \mathrm{~kg} / \mathrm{ha}$ de GLI. O melhor ajuste para o efeito das interações de doses crescentes de AF com 1,50 e 2,25 kg/ha de GLI foi o modelo quadrático. Aumentos em altura das plantas foram obtidos até $150 \mathrm{ppm}$ de $\mathrm{AF}$, diminuindo a partir deste ponto. Na dose máxima de $3,0 \mathrm{~kg} / \mathrm{ha}$ de GLI a resposta ao $\mathrm{AF}$ foi cúbica, sendo que a $75 \mathrm{ppm}$ de $\mathrm{AF}$ ocorreu a altura máxima das plantas. Aumentos nas doses de GLI (Figura 2) também resultaram em aumentos de altura das plantas de soja. Nas interações de GLI com 225 ppm de

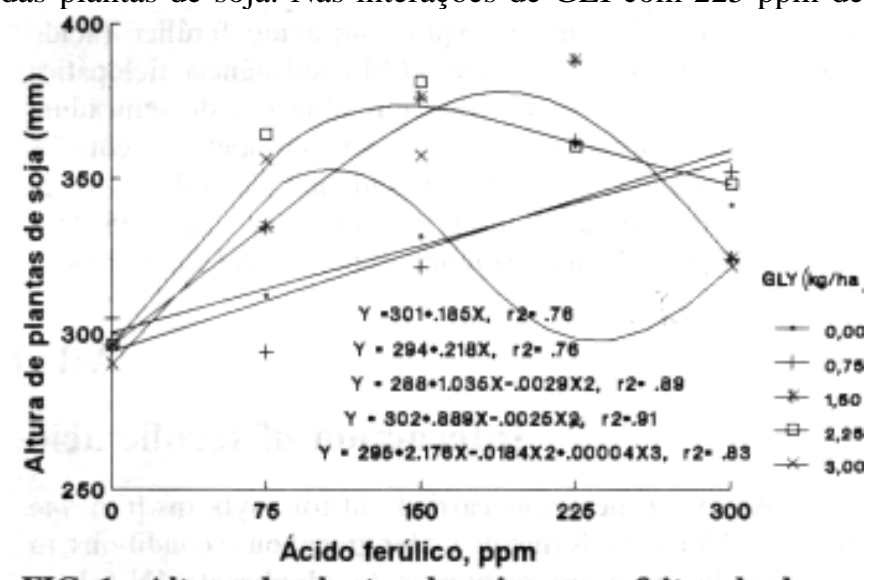

FIG. 1 - Altura de plantas de soja para efeitos de doses crescentes de ácido ferúlico, em diferentes níveis de glifosate.

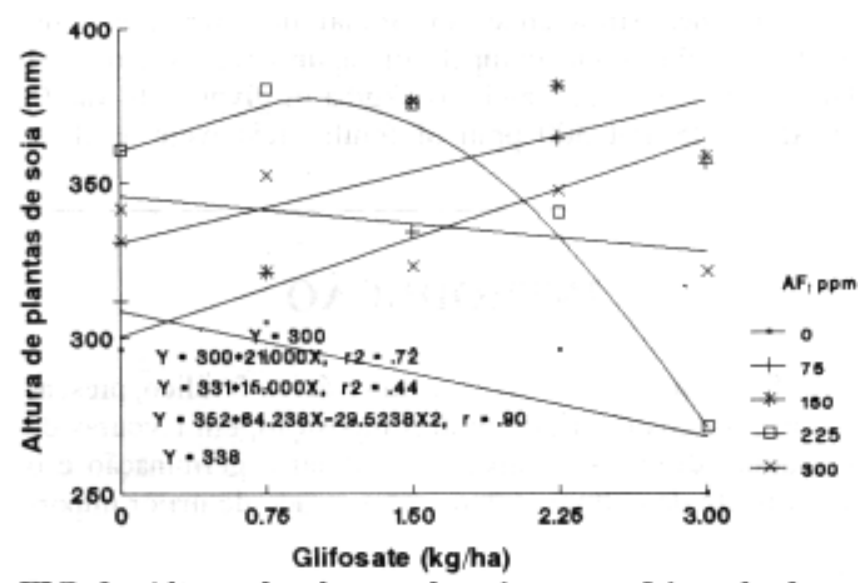

FIG. 2 - Altura de plantas de soja para efeitos de doses crescentes de glifosate, em diferentes níveis de ácido ferúlico. 
AF, o melhor ajuste foi o quadrático, resultando em aumentos de altura das plantas até $0,75 \mathrm{~kg} / \mathrm{ha}$ de GLI, declinando com maiores doses. Efeitos sobre a altura de plantas, devidos a GLI nas doses de 0 e 300 ppm de AF, não foram significativos.

A biomassa fresca da parte aérea da soja (Figura 3) aumentou significativamente até $150 \mathrm{ppm}$ de AF, em todas as combinações de GLI, representado pela média, sendo que nas doses maiores de AF houve menor produção de biomassa, que se reduziu ao nível da testemunha. Por sua vez, a biomassa seca das raízes da soja decresceu com maiores doses de AF com $0,0 \mathrm{~kg} / \mathrm{ha}$ de GLI.

A biomassa fresca da parte aérea (Figura 4) decresceu com maiores doses de GLI, em todas as combinações de AF, representado pela média. De modo semelhante, a biomassa seca das raízes decresceu com maiores doses de GLI, com 0 ppm de AF. Observa-se que o AF tem efeito no aumento de altura das plantas de soja, incrementando a biomassa da parte aérea, mas reduzindo a das raízes, à semelhança de substâncias indutoras de crescimento. Por outro lado, o GLI aumenta a altura das plantas de soja, com redução da biomassa da parte aérea e das raízes.

O aumento da altura das plantas de soja, causado por AF ou GLI, é uma característica desejável, significando uma vantagem competitiva por luz em relação às plantas daninhas. No entanto, o estiolamento da planta com redução da biomassa da parte aérea poderia deixar a planta susceptível à quebra do caule ou ao acamamento. A inibição da germinação e atrasos da emergência, com redução do crescimento de espécies de plantas daninhas, devidos a efeitos de substâncias alelopáticas, como o AF, têm sido observados (Almeida e Rodrigues, 1984; Liebl \& Worsham, 1983;

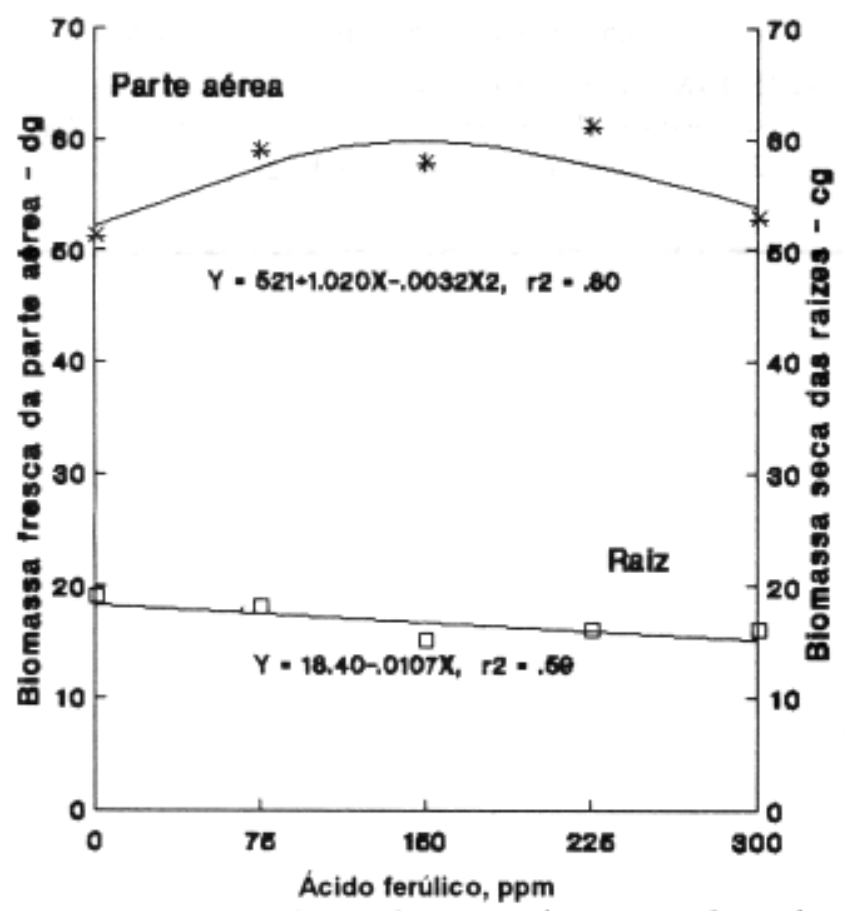

FIG. 3 - Biomassa fresca da parte aérea e seca das raízes de plantas de soja para efeitos de doses crescentes de ácido ferúlico, em diferentes níveis de glifosate, representadas pela média dos dados.

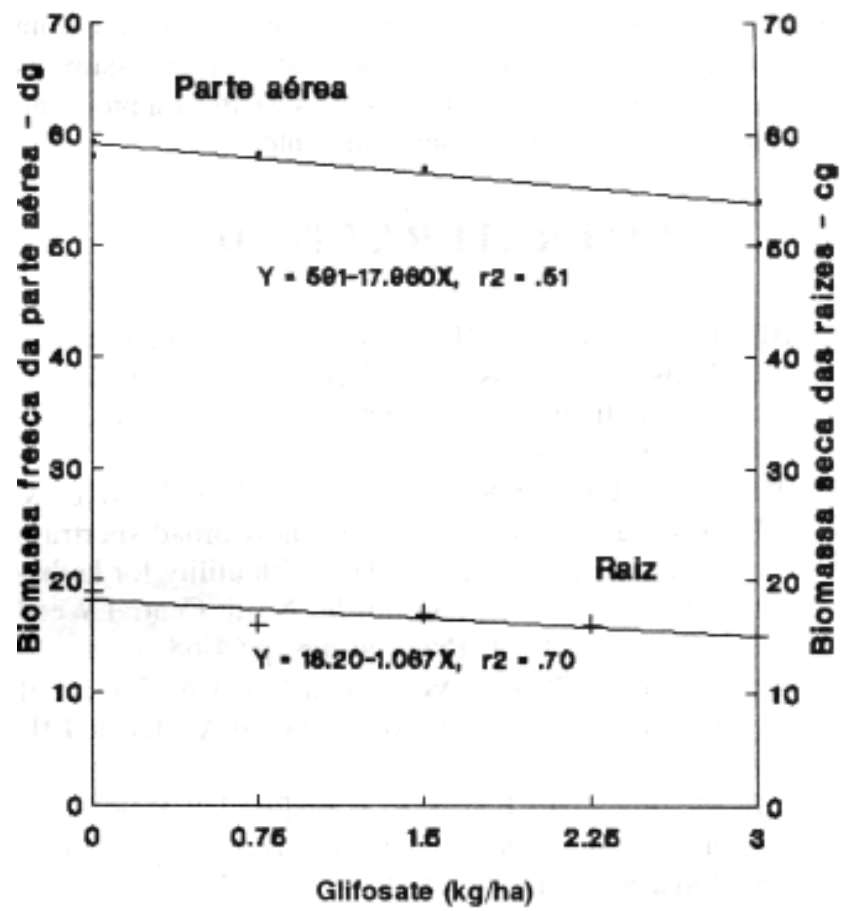

FIG. 4 - Biomassa fresca da parte aérea e seca das raízes de plantas de soja para efeitos de doses crescentes de glifosate, em diferentes níveis de ácido ferúlico, representadas pela média dos dados.

Rodrigues et al., 1982; Steinsiek et al., 1980; Voll, 1986; Williamson, 1978) e seríam desejáveis no sistema de competição com a cultura por luz.

Aumentos de biomassa da parte aérea da soja devidos ao AF, como neste experimento, poderiam significar aumento de produção. Redução da biomassa da soja tem ocorrido, sendo comparativamente menor do que em espécies daninhas (Volt, 1986). Efeitos positivos de GLI no aumento de biomassa, relatados para milho e soja (Rodrigues et al., 1982) e sorgo (Baur et al., 1976), não foram observados neste experimento. Este efeito justificaria maiores produções de soja em certos anos para glifosate, comparado com paraquat, às vezes relatado como resultado de um controle de gramíneas por um período mais prolongado (Hardcastle, 1972; Wor sham \& Lewis, 1972). A redução da biomassa das raízes pode influir na quantidade de absorção de água, nutrientes, ou de substâncias como herbicidas. Neste caso, menores quantidades destes seriam absorvidas pela soja, reduzindo possíveis danos, às vezes verificados no campo. Dependendo da susceptibilidade da espécie, plantas daninhas pode riam manifestar semelhantes respostas. Este efeito, no caso, é possível de ocorrer em função de AF, como uma das substâncias liberadas pelas restevas de culturas anteriores, deixadas cobrindo a superfície do solo em semeadura direta, ou por GLI. A absorção de glifosate seria facilitada em solos arenosos (de menor absorção), com suficiente umidade no solo, uma vez que a adsorção deste às partículas do solo é elevada em função das suas cargas positivas, enquanto que os colóides em solos argilosos são predominantemente negativos (Baird et al., 1971).

Em condições de resteva em lavouras sob semeadura direta e com o uso de glifosate, é possível a ocorrência de

Planta Daninha, v. 11, n. 1/2, 1993. 
plantas de soja com maior altura e biomassa aérea e com redução da biomassa radicular, podendo afetar, assim, as relações com plantas daninhas presentes na área e a produção da cultura, variando com o meio ambiente.

\section{LITERATURA CITADA}

ALMEIDA, F.S. \& RODRIGUES, B.N. Plantio Direto. In: Guia de Herbicidas: Contribuição para o uso adequado em plantio direto e convencional. Londrina, IAPAR, 1984. pp.341-399.

BAIRD, D.D.; UPCHURCH, R.P.; HOMESLY, W.B. \& PRANZ, J.E. Introduction of a new broad spertrum postemergence herbicide class with utility for herbaceus perennial weed control. In: North Central Weed Sci. Conf., 26, 1971. Proceedings. p.64-68.

BAUR, J.R.; BOVERY, R.W. \& VEECH, J.A. Effects of glyphosate on sorghum growth. Weed Abstract, 191: 79, 1976.

COCHRAN, V.L.; ELLIOT, L.F. \& PAPENDICK, R.I. The production of phytotoxins from surface crop residues Soil Sci. Soc. Am. J., 41: 903-908, 1977.

COLLINS, F.C. \& CAVINESS, C.E. Growth of soybeans on wheat straw residue. In: Amer. Soc. Agron.: Crop Sci. Soc. Amer. \& Soil Sci. Soc. Amer., 70, Chicago, 1978. Agronomy Abstracts. p.92.

GUENZI, W.D. \& McCALLA, T.M. Inhibition of germination and seedling development by crop residues. In: Soil. Sci. Soc., 26, 1962. Proceedings, p.456-458.

GUENZI, W.D. \& McCALLA, T.M. Phenolic acids in oats, wheat, sorghum, and corn residues and their phytotoxicity. Agronomy Journal, 58: 303-304, 1966.

HARDCASTLE, W.S. Weed control in conventional, nontilled and stable bed plantings of soybeans. In: South. Weed Sci. Soc., 26, New Orleans, 1972. Proceedings. p.88.
LIEBL, R.A. \& WORSHAM, A.D. Tillage and mulch effects on morning glory (Ipomoea spp.) and certain other weed species. In: South. Weed Sci. Soc., 36, Biloxi, 1983. Proceedings. p.405-414.

PAPENDICK, R.I. \& MILLER, D.E. Conservation tillage systems in the Pacific Northwest. Journal of Soil Conservation, 32:49-56, 1977.

PATRICK, Z.A. \& KOCH, L.W. Inhibition of respiration, germination, and growth by substances arising during the decommposition of certain plant residues in the soil. Can adian Journal of Botany, 36: 621-647, 1958.

RODRIGUES, J.J.V.; WORSHAM, A.D. \& CORBIN, F.T. Exudation of glyphosate from wheat(Triticum aestiwun) plants and on interplanted corn (Zea mays) and soybean (Glycine max). Weed Science, Champaign, 30: 316320, 1982.

STEINSIEK, J.W.; OLIVER, L.R. \& COLLINS, F.C. The effect of phytotoxic substances from wheat straw on selected weeds. In: South. Weed Sci. Soc., 33, Hot Springs, 1980. Proceedings. p.65.

VOLL, E. Efeitos do ácido ferúlico em interações com densidades de soja [Glycine $\max$ (L.) Merr. cv. Bragg] e caruru (Amaranthus retroflexus L.). In: Congr. Bras. Herb. Pl. Dan., 16, Campo Grande, 1986. Resumos. p.7.

WILLIAMSON, D.H. Effects of glyphosate [N-(phosphonomethyl) gycine] on conventionally and no-till planted corn (Zea mays L.) and soybeans (Glycine max L.). Raleigh, NCSU, 1978.76p. Tese Mestrado.

WORSHAM, A.D. \& LEWIS, W.M. No-tillage corn and soybeans with glyphosate. In: South. Weed Sci. Soc., 26, New Orleans, 1972. Proceedings. p.42. 